ring-shaped and arcuate outcrops picked out in strong relief. They are, however, believed to be associated with circular fracturing, and in this respect they may differ from the Southern Rhodesia occurrences, which are also different petrologically. Nothing is as yet known as to the age of the Nigerian ring-complexes other than that they are post-Basement complex and pre-Cretaceous, but there are grounds for believing that their age is much nearer Cretaceous than pre-Cambrian.

\author{
Geological SurVey, \\ Nigeria. \\ 24th September, 1946.
}

F. DiXeY.

\title{
CRYSTALLIZATION OF PLUTONIC AND HYPABYSSAL ROCKS
}

SIR,-In his paper on " The order of Crystallization of the Minerals in some Caledonian Plutonic and Hypabyssal Rocks" (Geol. Mag., 83, pp. 206-216), Dr. Nockolds justly remarks that " the determination of the true order of crystallization of minerals in a plutonic intrusion is not an easy matter". It would have been helpful, however, towards forming an estimate of his findings had he referred to the criteria actually adopted in his research. The following observations may nevertheless be made on his conclusions whatever the criteria used.

1. Contrary to Dr. Nockolds's statement on p. 209, discontinuous reaction can occur in a "eutectic system", and will take place if the liquid-solid equilibrium curve, or surface, has a concealed maximum.

2 . The only explanation for the successive cessations of crystallization amongst the ferromagnesian minerals (diagram, p. 209), is the assumption of a reaction-series : olivine $\rightarrow$ rhombic pyroxene $\rightarrow$ augite $\rightarrow$ hornblende $\rightarrow$ biotite. Augite is the only bridge between the crystallization periods of rhombic pyroxene and hornblende, and yet it is stated (p. 209) that rhombic pyroxene and augite "crystallize out side by side during part of their range". It would be interesting to know how Dr. Nockolds would show this on a phase diagram.

3. On p. 209, Dr. Nockolds states that " the ferromagnesian minerals ... all cease to crystallize before the final stage of the crystallization history is reached". No phase can cease to crystallize in a cooling system unless, by reaction with the liquid another phase takes its place. The other phases present are plagioclase, potash felspar, and quartz, crystallizing along with the last member of the ferromagnesian " reactionseries ", biotite (p. 209), so that the ferromagnesian minerals are clearly not replaced in this way. No explanation is advanced by Dr. Nockolds of the remarkable cessation of crystallization of these minerals before the eutectic was reached.

4. Dr. Nockolds gives " the crystallization curve for the Caledonian igneous rocks" and states (p. 214): "The crystallization curve constructed applies to the parental magma, the pyroxene-mica-diorite. If a liquid represented by any other point on the curve was separated from the earlier formed crystals, its curve of crystallization would follow a different course." The curve followed by the rocks thus shows the 


\section{Correspondence}

crystallization of a liquid in contact with its deposited crystals. Dr. Nockolds's postulated plagioclase-potash felspar-quartz eutectic (p. 210), without iron and magnesium, is a physico-chemical impossibility for a liquid which started with these components.

5. Dr. Nockolds states (p. 214) that the crystallization curve determined by study of the rocks coincides with the theoretical curve followed by a liquid in contact with its early crystals. This evidence is conclusive that the postulated differentiation of various rock-types from a homogeneous magma, by the separation of early crystals from the liquid, did not take place.

6. Dealing with the pegmatites, Dr. Nockolds states (p. 216) that "it does not appear likely that they will fall on the ternary cotectic curve". He explains this anomaly by pointing out their richness in volatile constituents "so that they no longer conform to laws applicable to more or less dry melts, like the aplites, but behave like watery solutions". This reversion to the old physico-chemical fallacy of believing fusion and solution to conform to different laws is unfortunate.

7. On p. 214 , Dr. Nockolds states that " differentiation took place in depth where a pyroxene-mica-diorite magma was undergoing progressive crystallization ". If the basic rocks were formed from this magma by the sinking of the early and heavy crystals, as appears to be the view of supporters of crystal-differentiation, the question why the basic rocks occur at the roofs of the Caledonian complexes arises. Does Dr. Nockolds continue to believe in "the intrusion of ... crystals with little or no magma"? (The Garabal Hill-Glen Fyne Igneous Complex. Quart. Journ. Geol. Soc., 1940, xcvi, p. 505.)

8. What Dr. Nockolds's research shows is in fact that a magmatic interpretation of the Scottish Caledonian complexes cannot be reconciled with the firmly established principles of phase-rule chemistry. The present writer has examined the Loch Doon complex in Galloway using the principles and technique of phase petrology (as enunciated by Professor S. J. Shand) to test the rival magmatic and metasomatic hypotheses. The evidence found has led to the conclusion that the Caledonian complex of Loch Doon consists of rocks which have never been magmatic and which must be classified with the metamorphic rather than with the igneous rocks. The anomalies in the magmatic hypothesis, apparent as a result of Dr. Nockolds's investigation, suggest that the metasomatic type of genesis found to apply to the Loch Doon complex is likely to be the rule rather than the exception among the Scottish Caledonian plutonics.

Donald C. McInTyRe.

Grant INSTITUTE OF GeOLOGY, UNIVERSITY OF EDINBURGH. 25th October, 1946. 